УДК 621.373.8.002.3; 620.171.3

DOI: https://doi.org/10.17308/kcmf.2019.21/757

Поступила в редакцию 06.05.2019

Подписана в печать 15.05.2019

\title{
СТРУКТУРНЫЕ И СПЕКТРАЛЬНЫЕ ОСОБЕННОСТИ КОМПОЗИТОВ НА ОСНОВЕ БЕЛКОВЫХ СРЕД С ОДНОСТЕННЫМИ УГЛЕРОДНЫМИ НАНОТРУБОКАМИ
}

\author{
() 2019 А. Ю. Герасименко ${ }^{1,2}$, Д. И. Рябкин ${ }^{1}$ \\ ${ }^{1}$ Национальный исследовательский университет «Московский институт электронной техники» \\ пл. Шокина, 1, 124498 Москва, Зеленоград, Российская Федерация \\ ${ }^{2}$ Первый Московский государственный медицинский университет им. И. М. Сеченова \\ Минздрава России (Сеченовский Университет) \\ Большая Пироговская ул., 2, стр. 4, 11943 Москва, Российская Федерация
}

\begin{abstract}
Аннотация. Исследованы структурные особенности нанокомпозитов, полученных при лазерном облучении водно-белковых сред с одностенными углеродными нанотрубками (ОУНТ), электродуговым (ОУНТІ) и газофазным методами (ОУНТII). С помощью спектроскопии комбинационного рассеяния нанокомпозитов определен нековалентный характер взаимодействия нанотрубок с молекулами белков. Белковая составляющая в нанокомпозитах подверглась необратимой денатурации и может выступать в качестве связующего биосовместимого материала, который является источником аминокислот для биологических тканей при имплантации нанокомпозитов в организм. Образцы, изготовленные из ОУНТІ, с меньшим диаметром и длиной имели наиболее однородную структуру. При увеличении концентрации от 0.01 до $0.1 \%$ происходило увеличение среднего размера микропор от 45 до 85 мкм и пористости образца в общем с 46 до 58 \%. При этом доля открытых пор для двух типов концентраций ОУНТІ составила 2 \% от общего объема композита. В нанокомпозитах на основе ОУНТІ показано наличие мезопор. Увеличение концентрации нанотрубок привело к уменьшению удельных значений поверхности и объема пор образца. Исследованные нанокомпозиты могут использоваться в качестве тканеинженерных матриц для восстановления объемных дефектов биологических тканей.
\end{abstract}

Ключевые слова: нанокомпозиты, лазерное излучение, структурирование, каркас, углеродные нанотрубки, белки, пористость.

\section{ВЕДЕНИЕ}

Одним из основных направлений в тканевой инженерии является поиск новых имитационных трехмерных 3D структур - синтетических имплантатов, которые должны стимулировать рост и дифференцировку клеток в процессе формирования ткани. Технология формирования объемных нанокомпозитов с функциональными свойствами, аналогичными свойствам межклеточного матрикса, имеет большой потенциал."

Углеродные наночастицы являются перспективными наполнителями для создания функциональных нанокомпозитов. Нитевидные структуры - углеродные нанотрубки (УНТ) привлекают большое внимание исследователей из различных областей науки и техники благодаря сво-

$\triangle$ Герасименко Александр Юрьевич, e-mail: gerasimenko@bms.zone ей высокой механической прочности, превосходным тепловым и электрическим свойствами [1]. На основе углеродных наночастиц проектируют и изготавливают функциональные наноматериалы, в том числе, самоорганизующиеся, путем функционализации наночастиц различными химическими группами и при их взаимодействии с органическими молекулами [2-6].

Одно из первых указаний на процесс воздействия лазерного излучения на углеродные нанотрубки с целью получения новых каркасных материалов содержится в [7], где использовалось непрерывное излучение $\mathrm{CO}_{2}$ лазера для создания каркасной морфологии многостенных углеродных нанотрубок (МУНТ) в фенольной смоле. В [8] показана возможность механического вращения УНТ при их возбуждении циркулярно поляризованным ИК излучением, распространяющимся вдоль нанотрубок. Момент инерции нанотруб- 
ки составил $28 \mathrm{GHz}$, а центробежное ускорение на поверхности трубки $0.5 \cdot 10^{12} \mathrm{~m} / \mathrm{s}^{2}$. Это значение на 2-5 порядков больше, чем создают быстрейшие центрифуги, однако из-за малости результирующей силы на каждом атоме углерода оно пренебрежимо по сравнению с действием обычной молекулярной силы связи.

С помощью лазерного испарения композиционной мишени на основе УНТ в матрице толуола удалось иммобилизировать и фиксировать нанотрубки с заданной сетеобразной морфологией на стеклянной подложке [9]. Данный процесс осуществляли импульсным лазером с длиной волны $248 \mathrm{~nm}$, длительностью импульсов $25 \mathrm{~ns}$ и частотой импульсов $10 \mathrm{~Hz}$. При постепенном увеличении плотности мощности действующего на УНТ лазерного излучения получено контролируемое введение дефектов в их структуру [10]. Дефекты УНТ могли быть местами связывания нанотрубок в упорядоченную сеть.

В последнее время появляется все больше статей, описывающих способы применения УНТ в биомедицинской инженерии тканей и органов. Нанотрубки используются в качестве каркасной структуры композиционных материалов для замещения дефектных полостей биологических тканей, поскольку могут улучшить механические свойства и биосовместимость жидких дисперсных сред и твердых композитов [6, 11, 12]. УНТ имеют размеры, близкие к размерам основных компонентов природного клеточного матрикса, а их механические свойства подобны свойствам протеиновых структур живого организма. Нанотрубки способны имитировать фибриллярный белок коллаген внеклеточного матрикса ввиду периодически повторяющихся дефектов в структуре УНТ, схожей со структурой коллагена [13].

Для создания биологических нанокомпозитов используются МУНТ и одностенные угле-

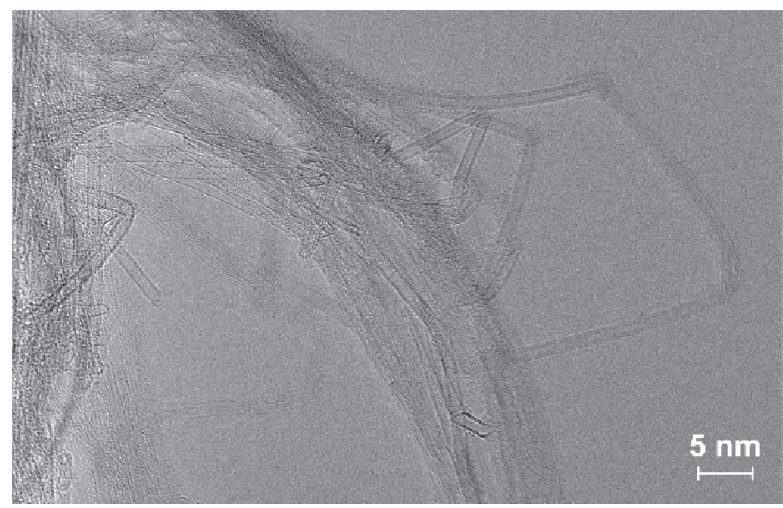

$a$ родные нанотрубки (ОУНТ), включенные в полимерные матрицы из поликапролактона, хитозана, полилактида, гидроксиапатита и т. д. [1418]. Применение композиционных материалов на основе УНТ в инженерии биологических тканей обеспечивает улучшение показателей развития клеток: их адгезии, пролиферации и дифференцировки [19].

В настоящей работе представлены результаты исследования нанокомпозитов, созданных методом лазерного испарения водно-белковой дисперсии углеродных нанотрубок. Показаны результаты взаимодействия компонентов композита друг с другом, а также представлен анализ внутренней и поверхностной структуры нанокомпозитов в зависимости от типа и концентрации используемых нанотрубок.

\section{ЭКСПЕРИМЕНТАЛЬНАЯ ЧАСТЬ}

Для изготовления нанокомпозитов использовались одностенные углеродные нанотрубки двух типов. Нанотрубки первого типа (ОУНТI) были синтезированы электродуговым методом на $\mathrm{Ni} / Y$ катализаторе, очищены на воздухе с промывкой $\mathrm{HCl}$ и функционализированы карбоксильными группами в смеси $\mathrm{HNO}_{3} / \mathrm{H}_{2} \mathrm{SO}_{4}$, с промывкой до нейтральной реакции. Средний диаметр нанотрубок составлял $1.4-1.8 \mathrm{~nm}$, длина 0.3-0.8 $\mu \mathrm{m}$, а удельная поверхность продукта равнялась $400 \mathrm{~m}^{2} / \mathrm{g}$. Степень чистоты ОУНТ составляла $97 \%$. Нанотрубки второго типа (ОУНTII) были поучены методом газофазного синтеза и очищены аналогичным методом, что и первый тип ОУНТІ. Средний диаметр составлял $\sim 2-3.5 \mathrm{~nm}$, их длина была более $5 \mu \mathrm{m}$, а удельная поверхность $420 \mathrm{~m}^{2} / \mathrm{g}$. Степень чистоты ОУНТІІ составляла $91 \%$.

На рис. 1 представлены изображения просвечивающей электронной микроскопии ОУНТІ

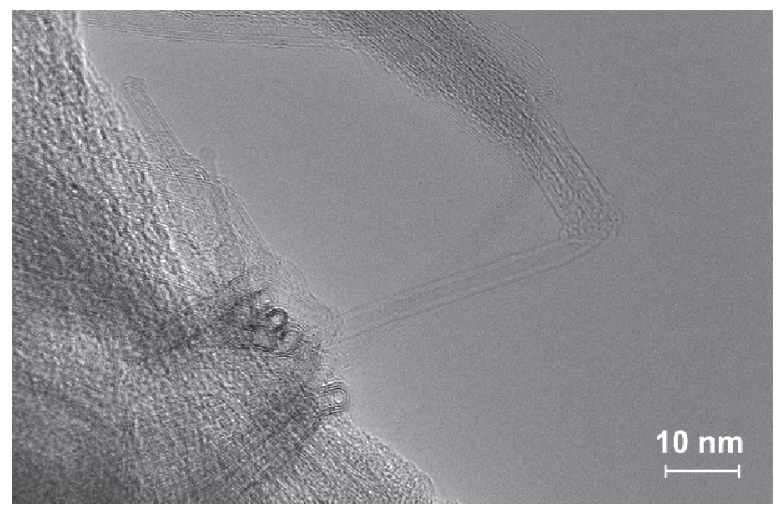

$b$

Рис. 1. Изображение ПЭМ ОУНТІ (a) и ОУНТІІ $(b)$

[Fig. 1. TEM images of SWCNTI $(a)$ and SWCNTII $(b)$ ] 
(рис. $1 a$ ) и ОУНТІІ (рис. $1 b$ ). Из рис. $1 a$ и $b$ видно, что отдельные нанотрубки под действием сил Ван дер Ваальса объединены в жгуты. Также заметно превышение размеров ОУНТII над размерами ОУНТI. Концентрация ОУНТ обоих типов составляла 0.1 и $0.01 \%$.

Для создания нанокомпозитов использовался лазерный метод, описанный в работе [19]. Однако в качестве белковой матрицы использовался водный раствор смеси бычьих белков альбумина (25 \%) и коллагена (2 \%). Внешний вид нанокомпозитов, поученных с использованием двух видов ОУНТІ (рис. $2 a$ ) и ОУНТІІ (рис. $2 b$ ).

Связывание молекул белков с углеродной составляющей описывалось методом спектроскопии комбинационного рассеяния (рамановской спектроскопии) с использованием установки inVia Qontor confocal Raman microscope (Renshaw, Германия). Спектр, возбуждаемый излучением лазера (длина волны $785 \mathrm{~nm}$ ), записывался с разрешением $4 \mathrm{~cm}^{-1}$, усреднялся по 150 сканам и подвергался обратному Фурье преобразованию.

Для проведения комплексного анализа структуры и микропористости нанокомпозитов был использован метод рентгеновской микротомографии. Использовалась установка Skyscan 1174 (Bruker, Бельгия). Напряжение рентгеновского источника не превышало $24 \mathrm{kV}$. Сила тока на катоде подбиралась таким образом, чтобы достигалось среднее значение интенсивности рентгеновского пучка в диапазоне 30-50 \% от максимального, и составляла $380 \mathrm{~mA}$.

Исследование удельных поверхности и объема пор образцов проводилось с использованием метода низкотемпературной азотной порометрии на установке «Сорбтометр-М» (3АО «Катакон», Россия). Образец подвергался дегазации и охлаждался до температуры 77 К в жидком азоте. Далее происходила адсорбция азота на поверхности образца. Увеличивалась доля азота до достижения парциального давления близкого к

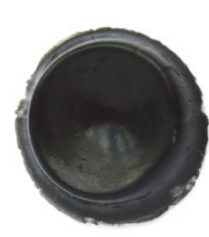

$a$ $b$

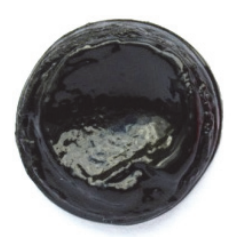

Рис. 2. Фотография образцов, полученных с использованием ОУНТI $(a)$ и ОУНТІ $(b)$

[Fig. 2. The photograph of samples obtained using SWCNTI $(a)$ and SWCNTII $(b)]$ насыщенному. После этого образец нагревался и происходила десорбция азота с поверхности образца. Объемная доля азота в смеси детектировалась с помощью детектора теплопроводности. Выходным рабочим сигналом детектора являлся преобразованный в электрический сигнал пик повышенной концентрации азота при его тепловой десорбции с поверхности образца. Площадь этого пика пропорциональна объему азота, десорбированного с поверхности образца. После достижения парциального давления, близкого к насыщенному, производилось построение изотермы десорбции. Для построения изотермы десорбции образец сначала насыщался азотом при его парциальном давлении близком к насыщенному, затем менялся состав газовой среды и измерялось количество десорбированного азота. Таким образом, итерационно строилась изотерма десорбции.

\section{РЕЗУЛЬТАТЫ И ИХ ОБСУЖДЕНИЕ \\ Спектроскопия комбинационного рассеяния нанокомпозитов}

Для исследования процесса связывания углеродных нанотрубок с органической частью (белки) в нанокомпозитах были измерены интерпретированы спектры комбинационного рассеяния (рис. 3).

В спектрах комбинационного рассеяния нанокомпозитов присутствуют характерные для одностенных углеродных нанотрубок пики: радиальная мода (от 100 до $300 \mathrm{~cm}^{-1}$ ), D-мода (около 1304-1310 $\mathrm{cm}^{-1}$ ) и 2D-мода (около $2590 \mathrm{~cm}^{-1}$ ), интенсивность которых в соотношении с G-модой (около $1590 \mathrm{~cm}^{-1}$ ) свидетельствует об отсутствии повреждений в структуре нанотрубок (перекручивание, разломы и т. д.) и о их хорошем структурном качестве. На рис. $3 c, d$ радиальная мода (RBM) представлена несколькими пиками, что говорит о присутствии в нанокомпозите углеродных нанотрубок разного диаметра. Исходя из формы пика G-моды, можно сделать вывод, что используемые нанотрубки проявляют полупроводниковые свойства. На рис. $3 a, b$ высокая интенсивность радиальной моды может быть связана с большим значением энергии возбуждающего пучка лазерного излучения, с помощью которого был получен спектр композита. То, что линия комбинационного рассеяния спектра в интервале между радиальной и $\mathrm{D}$ модами проходит значительно выше нулевой отметки, свидетельствует о присутствии в композите белков. Под воздействием лазерного излучения, с помощью которого были получены нанокомпозиты, 

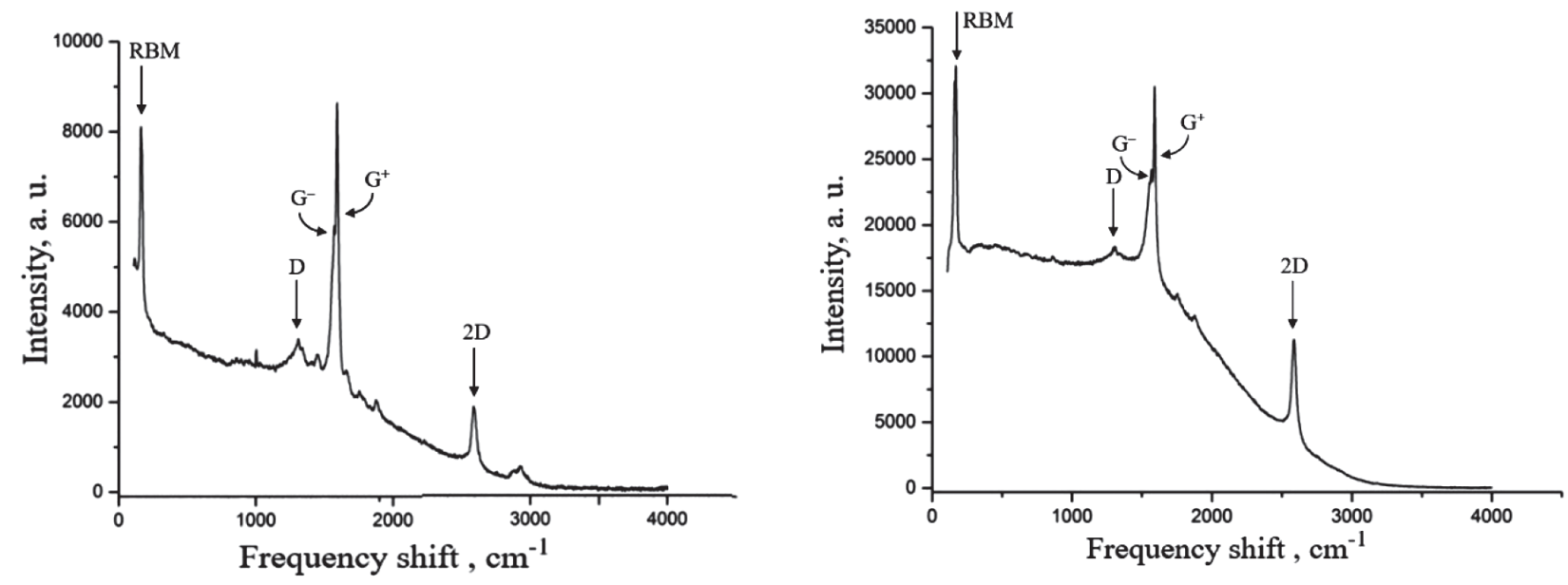

SWCNTI $-0,01 \%$
$a$

SWCNTI $-0,1 \%$
$b$
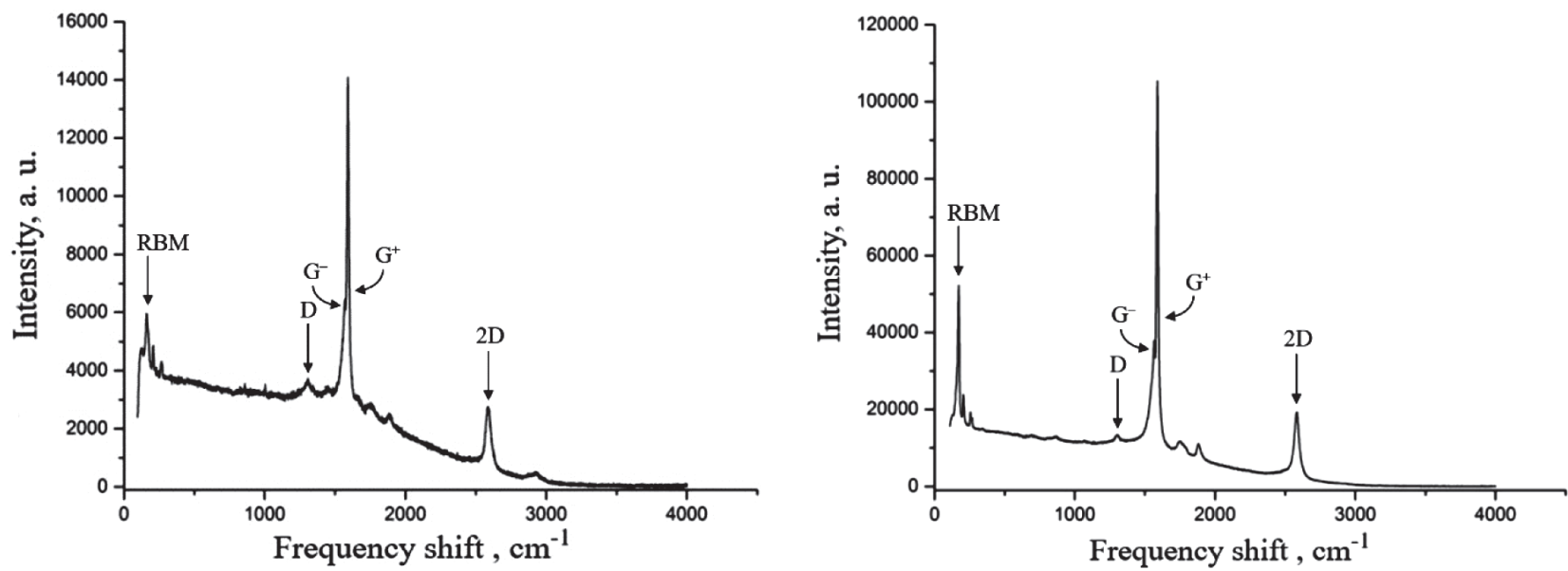

SWCNTII - 0,01\%

SWCNTII - 0,1\%\%

$d$

Рис. 3. Спектры комбинационного рассеяния нанокомпозитов с различной концентрацией нанотрубок: ОУНТІ - $0.01 \%(a)$, ОУНТІ - $0.1 \%(b)$, ОУНТІ - $0.01 \%(c)$, ОУНТІ $-0.1 \%(d)$

[Fig. 3. Raman spectra of nanocomposites with different nanotubes concentrations: SWCNTI - $0.01 \%(a)$, SWCNTI - $0.1 \%(b)$, SWCNTII - $0.01 \%(c)$, SWCNTII - $0.1 \%(d)]$

белки альбумин и коллаген подверглись процессу необратимой денатурации (нагрев дисперсии лазерным излучением выше $\left.100^{\circ} \mathrm{C}\right)$. Степень повреждения структуры белков можно оценить по наличию пиков амидной группы: наличие слабого пика на $1656 \mathrm{~cm}^{-1}$ (Амид I, присутствие связей $\mathrm{C}=\mathrm{O}$ ) говорит о значительных повреждениях во вторичной структуре белков. Полоса Амид II слабо проявляется в спектре комбинационного рассеяния и поэтому не используется для анализа внутренней структуры белков. Полоса Амид III (около $1300 \mathrm{~cm}^{-1}$ ) совпадает с интенсивным пиком в области D-моды, из-за это- го не представляется возможным сделать вывод о произошедших повреждениях во вторичной и третичной структуре белка (альфа-спираль и бета-структура). Небольшой острый пик около $1000 \mathrm{~cm}^{-1}$ говорит о наличие аминокислоты фенилаланина, по которой нормализуют полученные спектры. Практически не наблюдается ярко выраженных пиков около $1010 \mathrm{~cm}^{-1}$, отвечающих за наличие Ван дер Ваальсовских взаимодействий между боковыми группами аминокислот в белках. При этом в диапазоне $500-550 \mathrm{~cm}^{-1}$ в спектре комбинационного рассеяния мало ярко выраженных пиков, что осложняет выявление 
присутствия дисульфидных мостиков в молекулах белка, удерживающих молекулу в форме спирали; заметен слабый пик относительно пиков углеродных нанотубок на $859 \mathrm{~cm}^{-1}$, что свидетельствует о присутствии аминокислоты тирозина в композитах. На спектре около $1550 \mathrm{~cm}^{-1}$ практически не проявляется полоса Амид II (параллельные/непараллельные бета-структуры), т. к. ее нельзя наблюдать в отсутствие резонансного возбуждения. На рисунках $3 a, c$ наблюдается пик около $2922 \mathrm{~cm}^{-1}$, что говорит о наличии частично неповрежденных связей С-Н (связи в аминокислотах).

\section{Рентгеновская микротомография нанокомпозитов}

Для исследования микроструктуры нанокомпозитов с использованием рентгеновской томографии образцы фиксировались на специально напечатанных предметных столиках из прозрачного для излучения полимера. Параметры сканирования выбирались в соответствии с плотностью и геометрическими размерами образцов. Шаг поворота составлял $0.2^{\circ}$ при вращении на $360^{\circ}$ образца вокруг своей оси. Это соответствовало 3500-4000 теневых проекций и пространственному разрешению до $10 \mu \mathrm{m}$. На рис. $4 a-d$ изображены теневые проекции образцов, фотографии которых представлены на рис. 2. На рис. $4 e-g$ изображены трехмерные визуализации нанокомпозитов, восстановленные по 3500-4000 теневым проекциям.

Двумерная визуализация нанокомпозита, сформированного с использованием ОУНТІ с концентрацией $0.01 \%$ показана на рис. $5 a$. На рисунке верхнее изображение показывает вид спереди, нижнее изображение - вид сверху. Для визуализации внутренней структуры нанокомпозитов были сделаны продольные срезы с шагом $100 \mu \mathrm{m}$ вдоль горизонтальной оси Z образца (красная линия на изображении). Основные срезы нанокомпозита на расстояниях $0.5,1.3$ и $1.7 \mathrm{~mm}$ от нижней точки образца представлены на рис. $5 a$. При бинаризации изображения был определен средний размер пор образца, который составил $45 \mu \mathrm{m}$. Практически весь объем образца был однороден с равномерным распределением пор. Наблюдалось несколько единичных пор, размер которых не превышал $80 \mu \mathrm{m}$. При увеличении концентрации ОУНТІ до $0.1 \%$ в составе дисперсии для формирования нанокомпозита методом лазерного испарения, было получено значительное увеличение полостей размером 100-120 $\mu \mathrm{m}$ (рис. $5 b$ ). При бинаризации изображения средний размер пор составлял $85 \mu \mathrm{m}$. В peзультате использования в качестве наполнителя нанокомпозита углеродных нанотрубок с большим диаметром ОУНТІІ с концентрацией 0.01 \% было получено значительное количество полостей с большим размером - 200-280 $\mu \mathrm{m}$ (рис. $5 c$ ). При этом бинарное изображение показало средний разброс размеров пор в районе $70 \mu \mathrm{m}$. Увеличение концентрации ОУНТІІ до 0.1 \% в составе нанокомпозита способствовало увеличению количества пор, однако, их диаметр уменьшился до 150-200 $\mu \mathrm{m}$ (рис. 5d). При этом количество пор большого размера увеличилось, и вырос средний размер пор в результате бинаризации изображения до $90 \mu \mathrm{m}$.

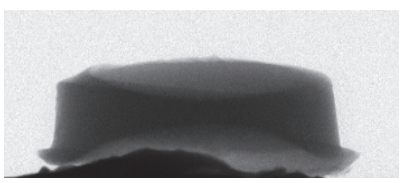

$a$

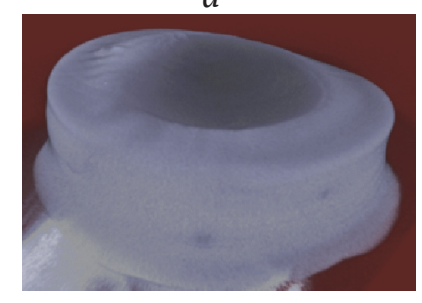

e

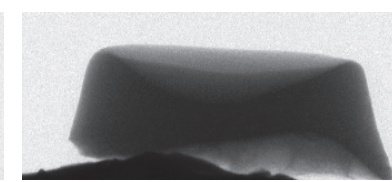

$b$

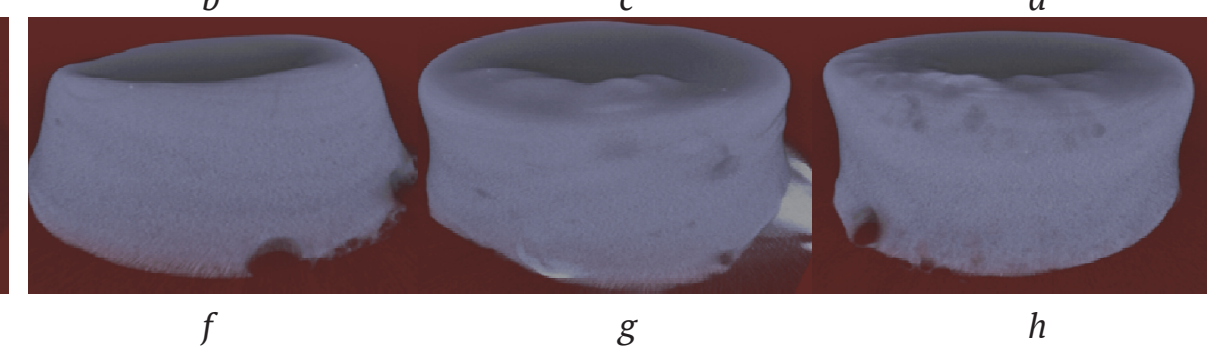

$f$

$g$

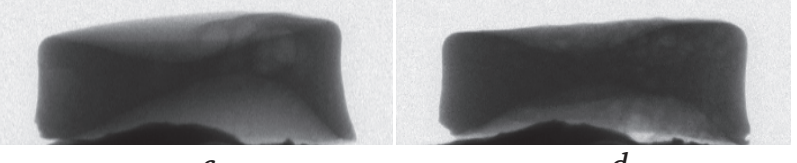

Рис. 4. Теневые проекции $(a-d)$ и трехмерная визуализация $(e-h)$ нанокомпозитов с различной концентрацией нанотрубок: ОУНТІ - 0.01 \% $(a, e)$, ОУНТI - 0.1 \% $(b, f)$, ОУНТII - $0.01 \%(c, g)$, ОУНTII $0.1 \%(d, h)$

[Fig. 4. Shadow projections $(a-d)$ and three-dimensional visualization $(e-h)$ of nanocomposites with different nanotubes concentrations: SWCNTI - $0.01 \%(a, e)$, SWCNTI $-0.1 \%(b, f)$, SWCNTII $-0.01 \%(c, g)$, SWCNTII $-0.1 \%(d, h)]$ 

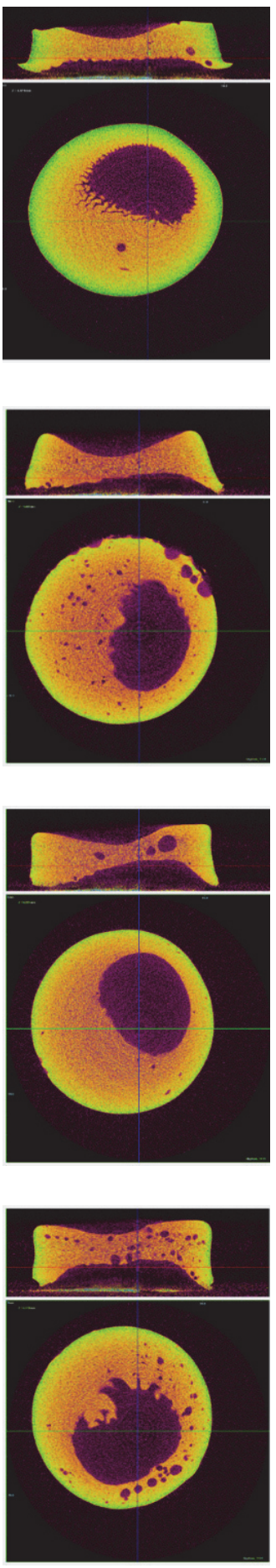

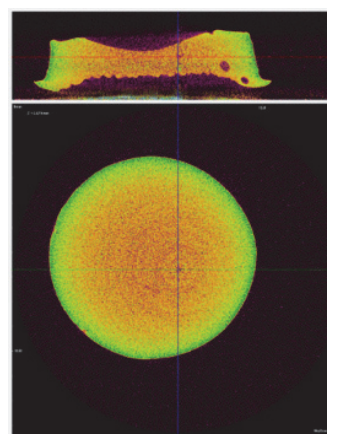

$a$

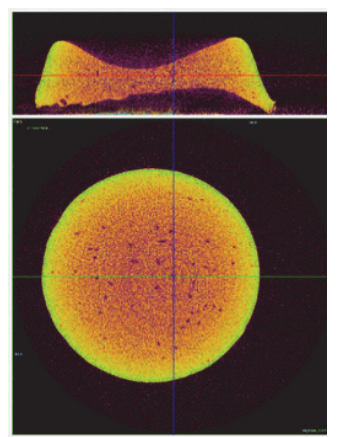

b

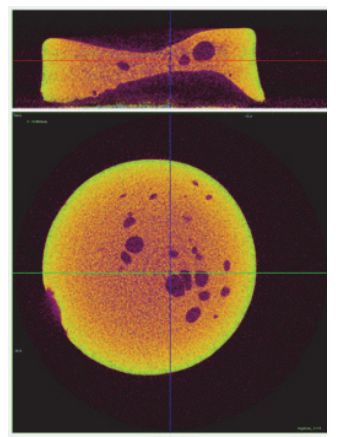

c
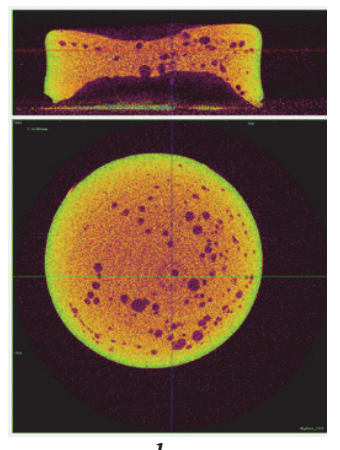

$d$
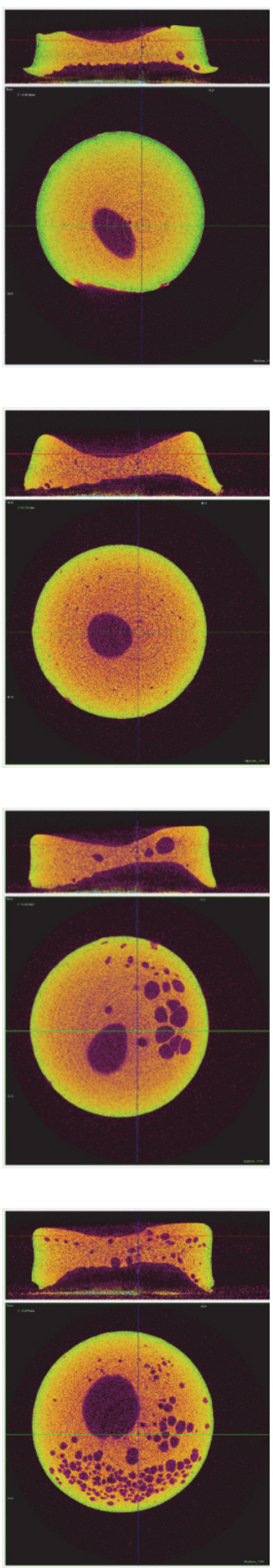

Рис. 5. Двумерная визуализация продольных срезов нанокомпозита на расстоянии от нижней точки образца 0.5 мм, 1.3 и 1, 7 мм (слева направо) с различной концентрацией нанотрубок: ОУНТI - 0.01 \% (a), ОУНТІ - $0.1 \%(b)$, ОУНТІ - $0.01 \%(c)$, ОУНTII $-0.1 \%(d)$

[Fig. 5. Two-dimensional visualization of nanocomposites longitudinal sections $0.5,1.3$ and $1.7 \mathrm{~mm}$ (from left to right) with concentration of nanotubes: SWCNTI - 0.01\% (a), SWCNTI - 0.1\% (b), SWCNTII - 0.01\% (c), SWCNTII - $0.1 \%(d)]$ 
По краям всех образцов нанокомпозитов наблюдалось уменьшение плотности структуры и увеличение количества пор. Вероятнее всего, более однородная центральная часть с мелкими порами была получена, ввиду неоднородного фронта распределения теплового нагрева гауссовым профилем лазерного излучения.

В табл. 1 представлены результаты количественного анализа нанокомпозитов, который был выполнен для трехмерных моделей каждого из образцов.

Из анализа структуры образцов, видно, что нанокомпозиты изготовленные из ОУНТІ с концентрацией 0.1 и $0.01 \%$ наиболее однородны. Получение образцов с использованием ОУНТІІ с концентрацией 0.1 и $0.01 \%$ сопровождалось большим количеством полостей, появление которых зависело от большого размера жгутов, в которые слипались исходные нанотрубки в белковой дисперсной среде за счет сил Ван-дер Ваальса. Для композитов на основе обоих типов ОУНТ было получено, что увеличение концентрации нанотрубок влечет за собой рост общего объема пор на 12 и 10 \% соответственно для ОУНТІ и ОУНТІ. При этом, доля открытых пор составляла 2 \% от всего объема образца для композитов с двумя концентрациями ОУНТІ. Такой же показатель для композитов на основе ОУНТІ был равен 5 и 8 \% соответственно для двух кон- центраций 0.01 и $0.1 \%$. Наличие открытых пор в композитных важное значение для неоиннервации и неоваскуляризации тканеинженерных имплантатов.

Дальнейшие исследования были проведены для нанокомпозитов из обоих концентраций ОУНТІ. Для этого из нанокомпозитов выделялся наиболее однородный фрагмент одинакового объема $\sim 1 \mathrm{~mm}^{3}$ и помещался в стеклянную ампулу и взвешивался на электронных весах. Масса образца определялась как разность масс ампулы с образцом и пустой ампулы. Затем ампула с образцом помещалась с станцию подготовки образцов анализатора удельной поверхности, где образец отжигался для удаления ранее адсорбированных веществ при температуре $50{ }^{\circ} \mathrm{C}$ в течение 1 часа.

Кривая адсорбции-десорбции строилась следующим образом. После дегазации ампула с образцом помещается в измерительный порт и охлаждается до 77 К в жидком азоте. В ампулу подавалась смесь азота и гелия (азот - адсорбат, гелий - носитель), в результате чего происходила адсорбция азота на поверхность образца. В смеси пошагово увеличивалась доля азота до достижения парциального давления близкого к насыщенному. На каждом шаге производилась выдержка образца при измеряемом парциальном давлении. После этого нанокомпозит нагревал-

Таблица 1. Количественный анализ нанокомпозитов

[Table 1. The quantitative analysis of nanocomposites]

\begin{tabular}{|c|c|c|c|c|}
\hline \multirow{2}{*}{$\begin{array}{l}\text { Параметры } \\
\text { [Parameters] }\end{array}$} & \multicolumn{4}{|c|}{$\begin{array}{l}\text { Тип и концентрация нанотрубок в составе образцов нанокомпозита } \\
\text { [The type and concentration of nanotubes in the nanocomposite samples } \\
\text { composition] }\end{array}$} \\
\hline & $\begin{array}{c}\text { OVHTI - } 0.01 \% \\
\text { [SWCNTI - } 0.01 \%]\end{array}$ & $\begin{array}{c}\text { OУHTI }-0.1 \% \\
{[\text { SWCNTI }-0.1 \%]}\end{array}$ & $\begin{array}{c}\text { OУHTII - } 0.01 \% \\
\text { [SWCNTII - } 0.01 \% \text { ] }\end{array}$ & $\begin{array}{c}\text { OУHTII - } 0.1 \% \\
\text { [SWCNTII - } 0.1 \% \text { ] }\end{array}$ \\
\hline $\begin{array}{l}\text { Минимальный диаметр } \\
\text { пор (мкм) } \\
\text { [Minimum pore diameter } \\
(\mu \mathrm{m})]\end{array}$ & 15 & 40 & 33 & 48 \\
\hline $\begin{array}{l}\text { Максимальный диаметр } \\
\text { пор (мкм) } \\
\text { [Maximum pore diameter } \\
(\mu \mathrm{m})]\end{array}$ & 80 & 120 & 314 & 180 \\
\hline $\begin{array}{l}\text { Средний размер пор } \\
\text { (мкм) } \\
\text { [Average pore size }(\mu \mathrm{m})]\end{array}$ & 45 & 85 & 97 & 70 \\
\hline $\begin{array}{l}\text { Пористость (\%) } \\
\text { [Porosity (\%)] }\end{array}$ & 46 & 58 & 64 & 73 \\
\hline $\begin{array}{l}\text { Доля открытых пор (\%) } \\
\text { [The proportion of open } \\
\text { pores (\%)] }\end{array}$ & 2 & 2 & 5 & 8 \\
\hline
\end{tabular}


ся, и происходила десорбция азота с поверхности образца. Объемная доля азота в смеси детектировалась с помощью детектора теплопроводности. Выходным рабочим сигналом детектора является преобразованный в электрический сигнал пик повышенной концентрации азота при его тепловой десорбции с поверхности образца. Площадь этого пика пропорциональна объему азота, десорбированного с поверхности образца. После достижения парциального давления, близкого к насыщенному, производилось построение изотермы десорбции. Для построения изотермы десорбции образец сначала насыщался азотом при его парциальном давлении близком к насыщенному, затем менялся состав газовой среды и измерялось количество десорбированного азота. Таким образом, итерационно строилась изотерма десорбции.

На рис. $6 a$ представлены изотермы адсорбции азота при 77 К на композитах. На всех изотермах имелись капиллярно-конденсационные гистерезисы, что говорит о наличии в образцах сквозных мезопор. Распределения пор по размерам, рассчитанные методом Баррета-ДжойнераХаленды (БЭТ), представлены на рис. $6 b$.

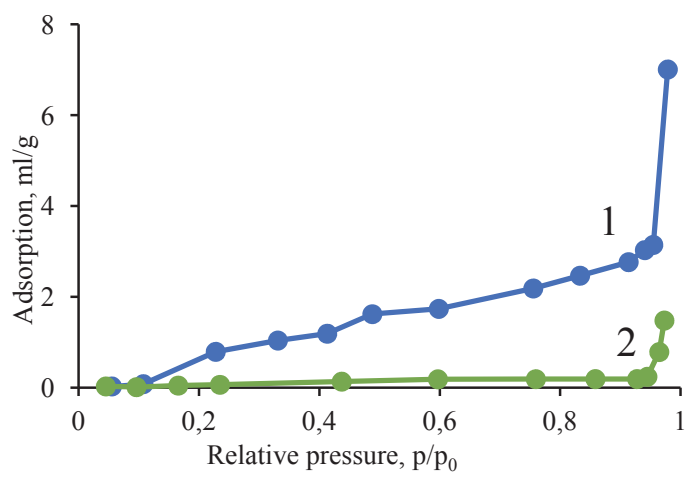

$a$
Рассчитанные из полученных изотерм адсорбции значения удельной поверхности методом БЭТ, удельного объема и среднего диаметра пор приведены в табл. 2. Можно видеть, что наибольшую удельную поверхность имеет образец с ОУНТІ - $0.01 \%$. Наибольший удельный объем пор был получен также для наименьшей концентрации. Однако средний диаметр пор для нанокомпозитов из ОУНТІ практически не отличался для обоих концентраций.

Из представленных на рис. $9 b, d$ зависимостей распределения пор по размерам видно, что кривые имеют несколько пиков, т. е. являются полимодальными. Определенные из данных распределений размеры пор в образцах представлены в табл. 3. Наибольший разброс по размерам пор был получен для нанокомпозитов, изготовленных из ОУНТІ - $0.01 \%$.

\section{ЗАКЛЮЧЕНИЕ И ВЫВОДЫ}

В работе были изготовлены нанокомпозиты из двух типов ОУНТІ и ОУНТII, синтезированных электродуговым и газофазным методом, соответственно. ОУНТІ имели наименьше размеры (диаметр и длина), в отличие от ОУНТ II.

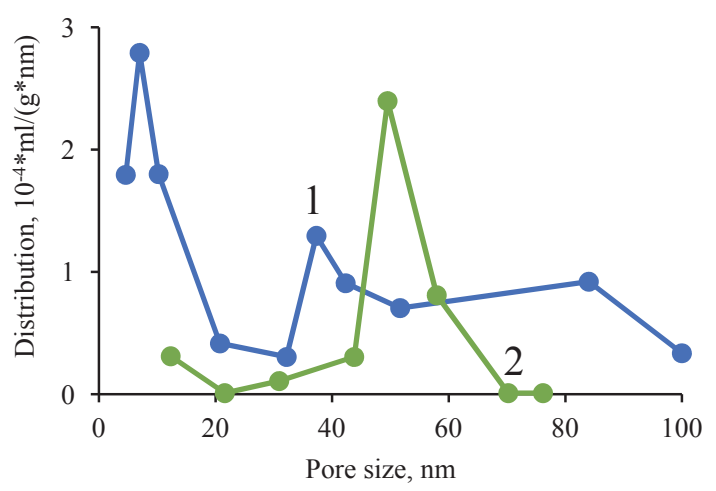

$b$

Рис. 6. Изотермы адсорбции азота нанокомпозитов при $77 \mathrm{~K}(a)$ и распределение пор по размерам в нанокомпозитах (b) при ОУНТI - 0.01 \% (кривые 1 ), ОУНТI - 0.1 \% (кривые 2 )

[Fig. 6. Isotherms of nitrogen nanocomposites adsorption at $77 \mathrm{~K}(a)$ and pore size distribution in nanocomposites $(b)$ with SWCNTI $-0.01 \%$ (curves 1 ), SWCNTI - $0.1 \%$ (curves 2 )]

Таблица 2. Удельные поверхность и объем пор нанокомпозитов

[Table 2. The nanocomposites specific surface area and pore volume]

\begin{tabular}{|c|c|c|c|}
\hline $\begin{array}{c}\text { Тип и концентрация нанотрубок в } \\
\text { составе нанокомпозита } \\
\text { [Type and concentration of nanotubes } \\
\text { in the composition of nanocomposite] }\end{array}$ & $\begin{array}{c}\text { Удельная поверх- } \\
\text { ность, } \mathrm{M}^{2} / \Gamma \\
\text { [Specific surface } \\
\text { area }\left(\mathrm{m}^{2} / \mathrm{g}\right) \text { ] }\end{array}$ & $\begin{array}{c}\text { Удельный } \\
\text { объем пор, мл/г } \\
\text { [Specific pore } \\
\text { volume }(\mathrm{ml} / \mathrm{g}) \text { ] }\end{array}$ & $\begin{array}{c}\text { Средний размер } \\
\text { пор, нм } \\
\text { [Average pore size } \\
(\mu \mathrm{m}) \text { ] }\end{array}$ \\
\hline $\begin{array}{c}\text { OУHTI - } 0.01 \% \\
\text { [SWCNTI - 0.01\%] }\end{array}$ & 3.341 & 0.011 & 46 \\
\hline $\begin{array}{c}\text { OУHTI - 0.1\% } \\
\text { [SWCNTI - 0.1 \%] }\end{array}$ & 0.515 & 0.002 & 49 \\
\hline
\end{tabular}


Таблица 3. Распределение размеров пор в нанокомпозитах

[Table 3. The nanocomposites pore size distribution]

\begin{tabular}{|c|c|c|}
\hline $\begin{array}{c}\text { Тип и концентрация ОУНТ в составе } \\
\text { нанокомпозита } \\
\text { [The type and concentration of SWNT in } \\
\text { the nanocomposite composition] }\end{array}$ & $\begin{array}{c}\text { OУHTI - 0.01\% } \\
\text { [SWCNTI - 0.01\%] }\end{array}$ & $\begin{array}{c}\text { OУHTI }-0.1 \% \\
\text { [SWCNTI - 0.1\%] }\end{array}$ \\
\hline Paзмер пор, нм & $5-20$ & $10-20$ \\
[Pore size (nm)] & $30-50$ & $40-70$ \\
\hline
\end{tabular}

Нанотрубки второго типа преимущественно представлены в слипшемся в жгуты виде за счет сил Ван дер Ваальса. При получении твердых нанокомпозитов методом лазерного испарения водной дисперсии углеродных нанотрубок в белковой матрице происходило локальное вскипание ОУНТ, которое сопровождалось появлением неоднородностей в виде выделяющегося газа и впоследствии пор. В качестве белков использовались бычьи сывороточный альбумин и коллаген.

Для исследования связывания белков с нанотрубками при формировании нанокомпозитов лазерным излучением были измерены спектры комбинационного рассеяния. Из спектров выявлены различия в морфологии типов используемых углеродных нанотрубок. В композитах из ОУНTII RBM мода на спектре представлена большим количеством пиков, что характеризует наличие трубок различного диаметра. Такая особенность присуща газофазному методу синтеза нанотрубок. При этом оба типа УНТ проявляют полупроводниковые свойства. Мода $\mathrm{G}$, отвечающая за полупроводниковые свойства композитов из ОУНТII, оказался слабо заметна в отличие от спектра для композитов из трубок ОУНТI. Из сравнения D моды с G модой видно, что нанотрубки не имеют механических повреждений в виде изломов или перекручивания. Пик около $2635 \mathrm{~cm}^{-1}$ является гармоникой второго порядка D моды, возникающей в результате двухфононного рассеяния второго порядка, приводящего к появлению неупругих фононов. В диапазоне от 280 до $1220 \mathrm{~cm}^{-1}$ проявились не характерные для неорганического компонента композита полосы белковых молекул, причем следует отметить, что по своему положению и форме полосы полностью совпадают с полосами альбумина и коллагена, но немного смещены относительно их нативного положения в низкочастотную область и имеют более пологую форму. Предполагается, что данные отличия связаны с нековалентным связыванием молекул компонентов нанокомпозитов. Под воздействием лазерного излу- чения углеродные нанотрубки способны формировать каркас [19], заполняемый путем внедрения в него или оборачивания вокруг него протеинового материала. При этом, появление полос альбумина более выражено в спектрах композитов, это позволяет сделать вывод о большей его устойчивости к термическому нагреву по сравнению с коллагеном. Для композитов на основе ОУНТІ характерно более слабое проявление белковых компонентов, по-видимому, это связано с более сильным влиянием нанотрубок во вклад спектра рассеяния нанокомпозита. Также пик в области D моды для композитов по форме немного отличался от чистой полосы одностенных нанотрубок на этой частоте, возможно потому, что оказала воздействие полоса Амид III, характерная для протеинов в этой области. Из анализа спектров можно сделать вывод о том, что белковая составляющая в нанокомпозитах подверглась необратимой денатурации и может выступать в качестве связующего биосовместимого материала, являющегося источником аминокислот для биологических тканей при имплантации нанокомпозитов в организм. Связывание компонентов дисперсии между собой происходит за счет так называемого накручивания длинных полипептидных цепочек белков на углеродные нанотрубки. В этом процессе лучше себя проявили нанотрубки ОУНТІ, имеющие в структуре карбоксильные функциональные группы.

Таким образом, при изготовлении нанокомпозитов углеродные нанотрубки активно поглощают излучение в ИК диапазоне, тем самым создавая дополнительный термический нагрев органических компонентов тканеинженерных конструкций. С ростом температуры растет число повреждений слабых связей третичной структуры белка, позволяющих молекуле видоизменять свое положение в пространстве. Предполагается, что нагрев от лазерного излучения и дополнительное тепло от нанотрубок ускоряют данные процессы и способствуют адгезии органической части композита к углеродному каркасу. 
Исследования нанокомпозитов с помощью рентгеновской микротомографии позволили сделать вывод о том, что внутренняя структура образцов, изготовленных из ОУНТІ, была наиболее однородна. При увеличении концентрации от 0.01 до $0.1 \%$ происходило увеличение среднего размера микропор от 45 до $85 \mu \mathrm{m}$ и пористости образца, в общем, с 46 до 58 \%. При этом доля открытых пор (преимущественно поверхностных) была одинаковой для двух типов концентраций нанотрубок первого типа в образцах и составила 2 \% от общего объема композита. Нанокомпозиты на основе ОУНTII с обеими концентрациями имели большой разброс размеров микропор от 33 до $314 \mu \mathrm{m}$. Вероятнее всего это было связано с менее однородным распределением ОУНТII и их агрегатов по объему дисперсии перед формированием композитов. Данные образцы с концентрацией нанотрубок 0.1 \% имели пористость до 73 \% при доле открытых пор 8 \%. Пористость нанокомпозитов для биомедицинских приложений важна для запуска процессов неоваскуляризации и неоиннервации в процесс восстановления дефектов биотканей.

Методом низкотемпературной азотной порометрии показано наличие в композитах на основе ОУНТІ наличие мезопор со средним размером до 46 и $49 \mathrm{~nm}$ соответственно для концентраций нанотрубок 0.01 и $0.1 \%$. При этом увеличение концентрации нанотрубок привело к уменьшению удельных значений поверхности и объема пор образца. Структурные характеристики наноразмерного масштаба композитов должны положительно влиять на адгезивные характеристики латеральных отростков клеток различных биотканей. Таким образом, исследованные в работе нанокомпозиты могут использоваться для восстановления объемных дефектов биологических тканей.

\section{ИСТОЧНИК ФИНАНСИРОВАНИЯ}

Исследование выполнено при поддержке проекта РФФИ и DFG № 19-51-12005.

\section{КОНФЛИКТ ИНТЕРЕСОВ}

Авторы декларируют отсутствие явных и потенциальных конфликтов интересов, связанных с публикацией настоящей статьи.

\section{СПИСОК ЛИТЕРАТУРЫ}

1. Елецкий А. В. Углеродные нанотрубки // Успехи физических наук, 1997, т. 167(9), с. 945-972. DOI: 10.3367/UFNr.0167.199709b.0945

2. Тучин А. В., Тяпкина В. А., Битюцкая Л. А., Бормонтов Е. Н. Функционализация закрытых ультракоротких углеродных нанотрубок $(5,5) / / \mathrm{KoH}^{-}$ денсированные среды и межфазные границы, 2016, т. 18, № 4, c. 568-577. URL: http://www.kcmf.vsu.ru/ resources/t_18_4_2016_015.pdf

3. Долгих И. И., Тяпкина В. А., Ковалева Т. А., Битюцкая Л. А. 3D Топологические изменения фермента глюкоамилазы при иммобилизации на ультракоротких углеродных нанотрубках // Конденсированные среды и межфазные границы, 2016, т. 18(4), c. 505-512. URL: http://www.kcmf.vsu.ru/resources/t_18_4_2016_007.pdf

4. Куликова Т. В., Тучин А. В., Аверин А. А., Тестов Д. А., Битюцкая Л. А., Бормонтов Е. Н. Структура и свойства самоорганизованных 2D- и 3D-композитов сурьма/углерод // Журнал технической физики, 2018, т. 88(7), с. 1025-1031. DOI: 10.21883/ JTF.2018.07.46171.2488

5. Kulikova T. V., Bityutskaya L. A., Tuchin A. V., Lisov E. V., Nesterov S. I., Averin A. A., Agapov B. L. Structural heterogeneities and electronic effects in self-organized core-shell type structures of $\mathrm{Sb} / /$ Letters on materials, 2017, v. 7(4), pp. 350-354. DOI: 10.22226/2410-3535-2017-4-350-354

6. Герасименко А. Ю. Лазерное структурирование ансамбля углеродных нанотрубок для создания биосовместимых упорядоченных композиционных материалов // Конденсированные среды и межфазные границы, 2017, т. 19(4), с. 489-501. DOI: 10.17308/kcmf.2017.19/227

7. Ma R. Z., Wei B. Q., Xu C. L., Liang J., Wu D. H. The morphology changes of carbon nanotubes under laser irradiation // Carbon, 2000, v. 38(4), pp. 636-638. DOI: 10.1016/s0008-6223(00)00008-7

8. Sadeghpour H. R., Brian E. Interaction of laser light and electrons with nanotubes // Physica Scripta, 2004, v. 110, pp. 262-267. DOI: 10.1238/physica. topical.110a00262

9. Gyorgy E., Perez del Pino A., Roqueta J., Ballesteros B., Cabana L., Tobias G. Effect of laser radiation on multi-wall carbon nanotubes: study of shell structure and immobilization process // J. of Nanoparticle Research, 2013, v. 15(8), p. 1852. DOI: 10.1007/s11051013-1852-6

10. Krasheninnikov A. V., Banhart F. Engineering of nanostructured carbon materials with electron or ion beams // Nature Materials, 2007, v. 6(10), pp. 723733. DOI: $10.1038 /$ nmat 1996

11. Ogihara N., Usui Y., Aoki K., Shimizu M., Narita N., Hara K., Nakamura K., Ishigaki N., Takanashi S., Okamoto M., Kato H., Haniu H., Ogiwara N., Nakayama N., Taruta S., Saito N. Biocompatibility and bone tissue compatibility of alumina ceramics reinforced with carbon nanotubes // Nanomedicine, 2012, v. 7(7), pp. 981-993. DOI: 10.2217/nnm.12.1

12. Abarrategi A., Gutiérrez M.C., Moreno-Vicente C., Hortigüela M.J., Ramos V., Lypez-Lacomba J. L., Ferrer M. L., del Monte F. Multiwall carbon 
nanotube scaffolds for tissue engineering purposes // Biomaterials, 2008, v. 29(1), pp. 94-102. DOI: 10.1016/ j.biomaterials.2007.09.021

13. Newman P., Minett A., Ellis-Behnke R., Zreiqat H. Carbon nanotubes: Their potential and pitfalls for bone tissue regeneration and engineering // Nanomedicine, 2013, v. 9(8), pp. 1139-1158. DOI: 10.1016/j.nano.2013.06.001

14. Sahithi K., Swetha M., Ramasamy K., Selvamurugan N. Polymeric composites containing carbon nanotubes for bone tissue engineering // International journal of biological macromolecules, 2010, v. 46(3). pp. 281-283. DOI: $10.1016 / \mathrm{j}$. ijbiomac.2010.01.006

15. Pan L., Pei X., He R., Wan Q., Wang J.// Colloids and Surfaces B: Biointerfaces, 2012, vol. 93, pp. 226234. https://doi.org/10.1016/j.colsurfb.2012.01.011

16. Mattioli-Belmonte M., Vozzi G, Whulanza Y., Seggiani M., Fantauzzi V., Orsini G., Ahluwalia A. Tuning polycaprolactone-carbon nanotube composites for bone tissue engineering scaffolds // Materials
Science and Engineering: C, 2012, v. 32(2), pp. 152-159. DOI: 10.1016/j.msec.2011.10.010

17. Venkatesan J., Qian Z., Ryu B., Kumar N. A., Kim S. Preparation and characterization of carbon nanotube-grafted-chitosan - Natural hydroxyapatite composite for bone tissue engineering // Carbohydrate Polymers, 2011, v. 83(2). pp. 569-577. DOI: $10.1016 /$ j. carbpol.2010.08.019

18. Lin C., Wang Y., Lai Y., Yang W., Jiao F., Zhang H., Shefang Ye., Zhang Q. Incorporation of carboxylation multiwalled carbon nanotubes into biodegradable poly(lactic-co-glycolic acid) for bone tissue engineering // Colloids and Surfaces B: Biointerfaces, 2011,v. 83(2), pp. 367-375.DOI: 10.1016/ j.colsurfb.2010.12.011

19. Gerasimenko A. Yu., Glukhova O. E., Savostyanov G. V., Podgaetsky V. M. Laser structuring of carbon nanotubes in the albumin matrix for the creation of composite biostructures // Journal of Biomedical Optics, 2017,v. 22(6), pp.065003-1-065003-8. DOI: 10.1117/1. jbo.22.6.065003

\title{
STRUCTURAL AND SPECTRAL CHARACTERISTICS OF COMPOSITES BASED ON PROTEIN CONDITIONS WITH SINGLE-WALLED CARBON NANOTUBES
}

\author{
@2019 A. Yu. Gerasimenko ${ }^{1,2} \bowtie$, D. I. Ryabkin ${ }^{1}$ \\ ${ }^{1}$ National Research University of Electronic Technology (MIET) \\ 1, Shokin sq., 124498 Moscow, Zelenograd, Russian Federation \\ ${ }^{2}$ I.M. Sechenov First Moscow State Medical University (Sechenov University) \\ 2, Bolshaya Pirogovskaya str., bld.4, 119435 Moscow, Russian Federation
}

\begin{abstract}
Purpose. The aim of the work is to study nanocomposites created by laser evaporation of waterprotein dispersion of carbon nanotubes. The studies are aimed to determine the features of the interaction between the composite components, as well as to the analysis of the internal and surface structures of nanocomposites, depending on the type and concentration of the used nanotubes.

Methods and methodology. For the manufacture of nanocomposites single-walled carbon nanotubes of two types were used. Nanotubes of the first type (SWCNTs I) were synthesized by the electric arc method on a Ni/Y catalyst. The average diameter of nanotubes was $1.4-1.8 \mathrm{~nm}$, length 0.3-0.8 microns. Nanotubes of the second type (SWCNTII) were obtained by the method of gas-phase synthesis. The average diameter was $\sim 2-3.5 \mathrm{~nm}$, their length was more than 5 microns. To create nanocomposites, a laser method was used to evaporate the waterprotein dispersion of nanotubes. However, the water dispertion of bovine albumin (25\%) and collagen ( $2 \%$ ) was used as a protein matrix. The binding of protein molecules to carbon component was described by Raman spectroscopy. To carry out a comprehensive analysis of the structure and microporosity of nanocomposites, the X-ray microtomography method was used.
\end{abstract}

$\triangle$ Gerasimenko Alexsander Yu., e-mail: gerasimenko@bms.zone 
The study of the specific surface and pore volume of the samples was carried out with the use of the method of low-temperature nitrogen porosimetry.

Results. There was a local boiling up of the dispersion of single-walled carbon nanotubes, which was accompanied by the appearance of inhomogeneities in the form of an evolved gas and subsequently produced the production of solid nanocomposites by laser evaporation of the aqueous dispersion of carbon nanotubes with the protein matrix. At the same time, the protein component in nanocomposites undergoes irreversible denaturation. It can be as a biocompatible binding material, which is a source of amino acids for biological tissues during the implantation of nanocomposites in the body. While manufacturing of nanocomposites, carbon nanotubes actively absorb radiation, creating an additional thermal heating of the organic components of tissue-engineering structures. As the temperature rises, the number of damages of the weak bonds in the tertiary structure of the protein, what allows the molecule to modify its position in space, increases. It is assumed that the heating from laser radiation and the additional heating from nanotubes accelerate these processes and contribute to the adhesion of the organic part of the composite to the carbon matrix. The internal structure of the SWCNTI nanocomposites was the most homogeneous. With an increase in concentration from 0.01 to $0.1 \%$, the average size of micropores increased from 45 to $85 \mu \mathrm{m}$ and the sample porosity in general from 46 to $58 \%$. The share of open pores for two types of SWCNTI concentrations was $2 \%$ of the total volume of the composite. SWCNTII-based nanocomposites with both concentrations had a wide range of micropore sizes from 33 to $314 \mu \mathrm{m}$. These samples with a concentration of $0.1 \%$ nanotubes had a porosity of up to $73 \%$ with an open pore fraction of $8 \%$. The presence of mesopores with an average size of up to 46 and $49 \mathrm{~nm}$ was found in SWCNTI-based composites, respectively, for concentrations of nanotubes of 0.01 and $0.1 \%$. An increase in the concentration of nanotubes led to a decrease in the specific values of the surface and pore volume of the sample.

Conclusions. In this work, nanocomposites were created by laser evaporation of the water-protein dispersion of carbon nanotubes. The features of the interaction between the components of the composite were identified. The analysis of the internal and surface structures of nanocomposites was carried out depending on the type and concentration of the used nanotubes. The structural characteristics of nanoscale composites should positively influence on the adhesive characteristics of the lateral processes of cells in various biotissues. The porosity of nanocomposites for biomedical applications is important for triggering the processes of neovascularization and neoinnervation in the repair of defects of biotissues. Thus, the nanocomposites studied in this work can be used as tissue-engineering matrixes to repair bulk defects of biological tissues.

Keywords: nanocomposites, laser radiation, structuring, framework, carbon nanotubes, proteins, porosity.

\section{SOURCE OF FINANCING}

The reported study was supported by a grant from the Russian Foundation for Basic Research and DFG (project No. 19-51-12005).

\section{CONFLICT OF INTEREST}

The authors declare the absence of obvious and potential conflicts of interest related to the publication of this article.

\section{REFERENCES}

1.Eletskii A. V. Carbon nanotubes. Phys. Usp., 1997, v. 40(9), pp. 899-924. DOI: 10.1070/PU1997v040n 09ABEH000282

2. Tuchin A. V., Tyapkina V. A., Bityutskaya L. A., Bormontov E. N. Functionalization of capped ultrashort single-walled carbon nanotube $(5,5)$. Condensed matter and interphases, 2016, v. 18(4), pp. 568-577.
URL:http://www.kcmf.vsu.ru/resources/t_18_4_2016_ 015.pdf (in Russ.)

3. Dolgikh I. I., Tyapkina V. A., Kovaleva T. A., Bityutskaya L. A. 3D Topological changes in enzyme glucoamylase when immobilized on ulrta0short carbon naotubes. Condensed matter and interphases, 2016, v. 18(4), pp. 505-512. URL: http://www.kcmf.vsu.ru/ resources/t_18_4_2016_007.pdf (in Russ.)

4. Kulikova T. V., Tuchin A. V., Testov D. A., Bityutskaya L. A., Bormontov E. N., Averin A. A. Structure and properties of self-organized 2D and 3D antimony/ carbon composites. Technical Physics, 2018, v. 63(7), pp. 995-1001. DOI: 10.1134/S1063784218070216

5. Kulikova T. V., Bityutskaya L. A., Tuchin A. V., Lisov E. V., Nesterov S. I., Averin A. A., Agapov B. L. Structural heterogeneities and electronic effects in self-organized core-shell type structures of Sb. Letters on materials, 2017 , v. 7 (4), pp. 350-354. DOI: 10.22226/2410-3535-2017-4-350-354 
6. Gerasimenko A. Yu. Laser structuring of the carbon nanotubes ensemble intended to form biocompatible ordered composite materials. Condensed matter and interphases, 2017, v. 19(4), pp. 489-501. DOI: $10.17308 / \mathrm{kcmf} .2017 .19 / 227$

7. Ma R. Z., Wei B. Q., Xu C. L., Liang J., Wu D. H. The morphology changes of carbon nanotubes under laser irradiation. Carbon, 2000, vol. 38(4), pp. 636-638. DOI: 10.1016/s0008-6223(00)00008-7

8. Sadeghpour H. R., Brian E. Interaction of laser light and electrons with nanotubes. Physica Scripta, 2004, vol. 110, pp. 262-267. DOI: 10.1238/physica. topical.110a00262

9. Gyorgy E., Perez del Pino A., Roqueta J., Ballesteros B., Cabana L., Tobias G. Effect of laser radiation on multi-wall carbon nanotubes: study of shell structure and immobilization process. J. of Nanoparticle Research, 2013, v. 15(8), p. 1852. DOI: 10.1007/s11051-013-1852-6

10. Krasheninnikov A. V., Banhart F. Engineering of nanostructured carbon materials with electron or ion beams. Nature Materials, 2007, v. 6(10), pp. 723733. DOI: $10.1038 /$ nmat 1996

11. Ogihara N., Usui Y., Aoki K., Shimizu M., Narita N., Hara K., Nakamura K., Ishigaki N., Takanashi S., Okamoto M., Kato H., Haniu H., Ogiwara N., Nakayama N., Taruta S., Saito N. Biocompatibility and bone tissue compatibility of alumina ceramics reinforced with carbon nanotubes. Nanomedicine, 2012, v. 7(7), pp. 981-993. DOI: 10.2217/nnm.12.1

12. Abarrategi A., Gutiérrez M.C., Moreno-Vicente C., Hortigüela M. J., Ramos V., Lypez-Lacomba J. L., Ferrer M. L., del Monte F. Multiwall carbon nanotube scaffolds for tissue engineering purposes. Biomaterials, 2008, v. 29(1), pp. 94-102. DOI: 10.1016/j.biomateria ls.2007.09.021
13. Newman P., Minett A., Ellis-Behnke R., Zreiqat H. Carbon nanotubes: Their potential and pitfalls for bone tissue regeneration and engineering. Nanomedicine, 2013, v. 9(8), pp. 1139-1158. DOI: 10.1016/j.nano.2013.06.001

14. Sahithi K., Swetha M., Ramasamy K., Selvamurugan N. Polymeric composites containing carbon nanotubes for bone tissue engineering. International journal of biological macromolecules, 2010, v. 46(3). pp. 281-283. DOI: 10.1016/j.ijbiomac.2010.01.006

15. Pan L., Pei X., He R., Wan Q., Wang J. Colloids and Surfaces B: Biointerfaces, 2012, vol. 93, pp. 226-234. https://doi.org/10.1016/j.colsurfb.2012.01.011

16. Mattioli-Belmonte M., Vozzi G, Whulanza Y., Seggiani M., Fantauzzi V., Orsini G., Ahluwalia A. Tuning polycaprolactone-carbon nanotube composites for bone tissue engineering scaffolds. Materials Science and Engineering: C, 2012, v. 32(2), pp. 152-159. DOI: 10.1016/j.msec.2011.10.010

17. Venkatesan J., Qian Z., Ryu B., Kumar N.A., Kim S. Preparation and characterization of carbon nanotube-grafted-chitosan - Natural hydroxyapatite composite for bone tissue engineering. Carbohydrate Polymers, 2011, v. 83(2). pp. 569-577. DOI: 10.1016/j. carbpol.2010.08.019

18. Lin C., Wang Y., Lai Y., Yang W., Jiao F., Zhang H., Shefang Ye., Zhang Q. Incorporation of carboxylation multiwalled carbon nanotubes into biodegradable poly(lactic-co-glycolic acid) for bone tissue engineering. Colloids and Surfaces B: Biointerfaces, 2011, v. 83(2), pp. 367-375. DOI: 10.1016/j. colsurfb.2010.12.011

19. Gerasimenko A. Yu., Glukhova O. E., Savostyanov G. V., Podgaetsky V. M. Laser structuring of carbon nanotubes in the albumin matrix for the creation of composite biostructures. Journal of Biomedical Optics, 2017, v. 22(6), pp.065003-1-0650038. DOI: 10.1117/1.jbo.22.6.065003
Герасименко Александр Юрьевич - к. ф.-м. н., доцент, с. н. с., Национальный исследовательский университет «МИЭТ», Москва, Зеленоград, Российская Федерация; e-mail: gerasimenko@ bms.zone. ORCID iD 0000-0001-6514-2411.

Рябкин Дмитрий Игоревич - аспирант, Национальный исследовательский университет «МИЭТ», Москва, Зеленоград, Российская Федерация; e-mail: ryabkin@bms.zone. ORCID iD 0000-0002-1327-5690.
Gerasimenko Alexander Yu. - Cand. Sci. (Phys.Math.), Associate Professor, Senior Researcher, National Research University of Electronic Technology MIET, Moscow, Zelenograd, Russian Federation; e-mail: gerasimenko@bms.zone. ORCID iD 00000001-6514-2411.

Ryabkin Dmitry I. - graduate student, National Research University of Electronic Technology MIET, Moscow, Zelenograd, Russian Federation; e-mail: ryabkin@bms.zone. ORCID iD 0000-00021327-5690. 